\title{
Atretic changes of follicular wall caused by destruction of the germinal disc region of an immature preovulatory follicle in the chicken: an electron microscope study
}

\author{
Y. Yoshimura ${ }^{1}$ and J. M. Bahr ${ }^{2}$ \\ ${ }^{1}$ Graduate School for International Development and Cooperation, Hiroshima University, \\ Higashi-Hiroshima 739, Japan; and ${ }^{2}$ Department of Animal Sciences, University of Illinois, Urbana, \\ IL 61801, USA
}

\begin{abstract}
The germinal disc of the female gamete and its overlying follicular wall (the germinal disc region) is hypothesized to play an important role in the regulation of follicular growth. The role of the germinal disc region in follicular growth in chickens was investigated by destroying the germinal disc region or an area opposite the germinal disc (control) of the second largest follicle $22-23 \mathrm{~h}$ before ovulation of the FI follicle, by localized freezing with solid $\mathrm{CO}_{2}$. Structural changes of the follicular wall (non-frozen region) were observed by electron microscopy $10-20 \mathrm{~h}$ after the destruction of the germinal disc region. Development of the inner structure of mitochondria in granulosa cells and accumulation of lipid droplets in thecal cells were observed in follicles $15 \mathrm{~h}$ after destruction of the germinal disc region. Twenty hours after destruction of the germinal disc region, follicles showed early signs of atresia (bursting atresia). Degenerative changes in follicles, including hydrolysis by lysosomal enzymes, were present in thecal fibroblast-like cells. Control follicles, in which an area opposite the germinal disc region was frozen $20 \mathrm{~h}$ before examination, had no degenerative features. These results provide further evidence that the germinal disc region is required for follicular growth.
\end{abstract}

\section{Introduction}

The chicken ovary contains numerous small white and yellow follicles and four or five large yellow follicles that are growing rapidly and are arranged in a hierarchy based on their size. The follicle consists of the oocyte and follicular wall. The germinal disc, approximately $2 \mathrm{~mm}$ in diameter, is located at the surface of the oocyte. This region is considered as the metabolic centre of the oocyte because ooplasmic organelles are condensed in this region. The granulosa layer and theca layer comprise the follicular wall which surrounds the oocyte.

Granulosa cells in the germinal disc region (germinal disc plus overlying granulosa layer) have a higher mitotic activity than do cells in other regions of the granulosa layer (Perry et al., 1978). This higher proliferation rate in the germinal disc region may depend on the serine protease, plasminogen activator (Tilly et al., 1992; Wang et al., 1993). Granulosa cells in the germinal disc region secrete greater amounts of plasminogen activator than do granulosa cells distal to the germinal disc region (Jackson et al., 1993a). In contrast, progesterone production by granulosa cells in the germinal disc region is lower than that by granulosa cells distal to the disc, suggesting that the granulosa cells of the germinal disc region are less mature than are cells in other regions of the granulosa layer (Marrone et al., 1990). Recent reports noted that the pre-

Received 21 April 1995. ovulatory follicle becomes atretic when the germinal disc region is destroyed by localized freezing, whereas atresia is not apparent when an area opposite the germinal disc is frozen (Jackson et al., 1993b; Yoshimura et al., 1994). These results suggest that the germinal disc region has a specific function in follicular growth. The aim of the present study was to determine how the germinal disc region influences the growth of follicles. Structural changes of the granulosa and theca layers induced by destruction of the germinal disc region of the second largest preovulatory follicle were examined.

\section{Materials and Methods}

Sixteen White Leghorn hens laying regular sequences of six or more eggs were used in this study. Birds were individually caged and maintained under a photoperiod of $14 \mathrm{~h}$ light: $10 \mathrm{~h}$ dark. Approximately $24 \mathrm{~h}$ before the treatment of follicles, the birds were injected i.v. with $0.5 \mathrm{ml}$ of Sudan black dye (Merk, Darmstadt) dissolved in ethanol at a concentration of $10 \mathrm{mg}$ $\mathrm{ml}^{-1}$ and diluted with equal parts of phosphate buffered saline before use. This injection of dye makes it easier to identify the germinal disc region because it appears as a white spot on the surface of the follicle. Birds underwent laparotomy under sodium pentobarbital anaesthesia $22-23 \mathrm{~h}$ before ovulation, and the second largest follicle was exposed. The germinal disc region was frozen by applying solid $\mathrm{CO}_{2}(2 \mathrm{~mm} \times 2 \mathrm{~mm})$ for 
I0s to the surface of the follicle. An area of equal size but opposite the germinal disc region was frozen in the same manner in control birds.

Birds were killed 10, 15, or $20 \mathrm{~h}$ after treatment of the follicle (four birds at each time period). Treated follicles were removed and fixed with Karnovsky's fixative $(4 \%(\mathrm{w} / \mathrm{v})$ paraformaldehyde and $5 \%(\mathrm{w} / \mathrm{v})$ glutaraldehyde in Millonig's buffer consisting of $0.12 \mathrm{~mol} \mathrm{NaH} \mathrm{PO}_{4} 1^{-1}$ and $1 \mathrm{~mol} \mathrm{NaOH} \mathrm{l}{ }^{-\mathrm{I}}$, $\mathrm{pH}$ 7.2) for I h. Yolk was washed out into Millonig's buffer, and the follicular wall was re-fixed in the same fixative for $3 \mathrm{~h}$ at $4^{\circ} \mathrm{C}$. Pieces of the follicular wall near the stalk, approximately $1 \mathrm{~mm} \times 2 \mathrm{~mm}$, were obtained. Tissues from the frozen area were not used for the microscopy. After washing with Millonig's buffer, tissues were post-fixed with $1.3 \%(\mathrm{w} / \mathrm{v})$ osmium tetroxide in Millonig's buffer for $2 \mathrm{~h}$ at $4^{\circ} \mathrm{C}$. Tissues were dehydrated with acetone and embedded in Epock 812. Thick sections $(1 \mu \mathrm{m})$ stained with toluidine blue were observed under a light microscope. Thin sections were stained with uranyl acetate and lead acetate and examined with a Hitachi 600A electron microscope at an accelerating voltage of $75 \mathrm{kV}$.

\section{Results}

Follicles in which an area opposite the germinal disc region was frozen $20 \mathrm{~h}$ before examination (control follicles) showed no signs of atresia (Fig. 1). The granulosa layer appeared as a single layer of cuboidal cells located between the perivitelline layer and basement membrane. Granulosa cells contained numerous cytoplasmic organelles such as mitochondria with lamellar cristae, rough endoplasmic reticulum, Golgi apparatus and dense bodies. Each granulosa cell formed interdigitations with adjacent cells, and cytoplasmic projections passed through the perivitelline layer reaching the oocyte surface (Fig. Ia). Fibroblasts and thecal interstitial cells were distributed throughout the connective tissue of the theca interna, and the capillary sinus was developed in this layer. Thecal interstitial cells were characterized by the presence of lipid droplets and mitochondria that contained tubular cristae (Fig. Ib). The theca externa consisted of fibroblast-like cells and a large amount of collagen fibres. Fibroblast-like cells contained dense bodies, well-developed rough endoplasmic reticulum, microfilaments, and other cytoplasmic organelles (Fig. 1c). These cytoplasmic structures in cells of the granulosa and theca layers of the control follicle are normal features of follicular tissues as previously observed.

Electron micrographs showed no atretic changes in the follicle $10 \mathrm{~h}$ after destruction of the germinal disc region. No atretic changes were observed at autopsy $15 \mathrm{~h}$ after destruction of the germinal disc region. However, electron microscopy revealed significant structural changes in the cytoplasm of granulosa cells, thecal interstitial cells, and fibroblast-like cells $15 \mathrm{~h}$ after destruction of the germinal disc region (Fig. 2). The density of the matrix and number of cristae had increased in the mitochondria of granulosa cells (Fig. 2a). The number of lipid droplets was increased in thecal interstitial cells, whereas cytoplasmic organelles did not show any significant change. In the theca interna, the cytoplasm and intercellular structure of fibroblasts showed the same features as those of normal follicles (Fig. 2b). Fibroblast-like cells in the theca externa
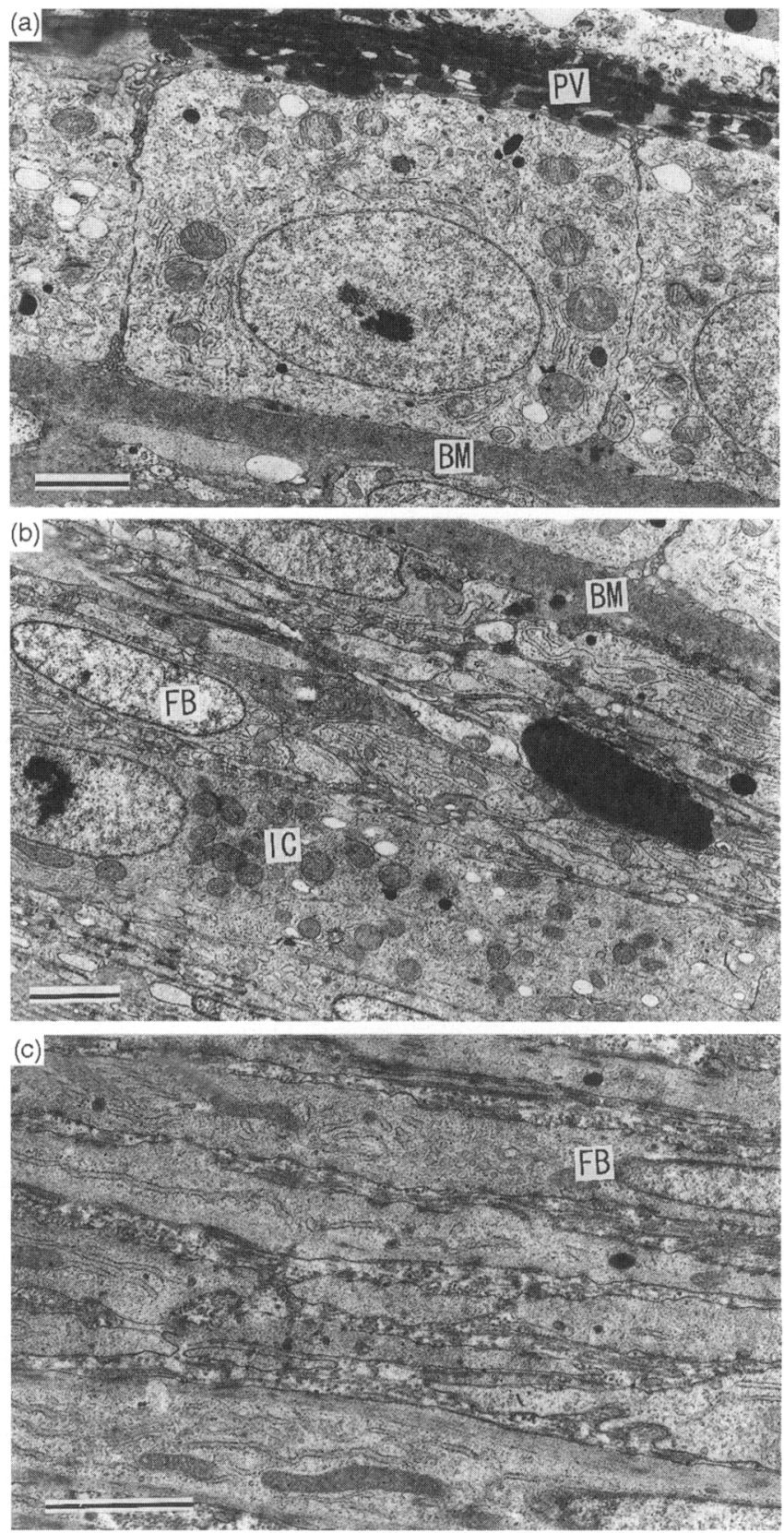

Fig. 1. Electron micrographs of the follicular wall of a control follicle from a chicken, in which an area, opposite, but of a similar size to, the germinal disc region was destroyed by localized freezing $20 \mathrm{~h}$ before examination. Micrographs are of the follicular wall excluding the frozen region. (a) Granulosa layer: granulosa cells contain numerous mitochondria with lamellar cristae and other cytoplasmic organelles. PV: perivitelline layer; $\mathrm{BM}$ : basement membrane. (b) Theca interna: interstitial cells (IC) and fibroblasts (FB) are distributed in the theca interna. The interstitial cells contain mitochondria with tubular cristae. (c) Theca externa: the theca externa is a dense connective tissue consisting of fibroblasts and collagenous fibres. Scale bars represent $2 \mu \mathrm{m}$.

contained numerous dense bodies, but no changes were observed in other organelles. Collagen fibres remained densely distributed in the intercellular space of fibroblast-like cells (Fig. 2c). 

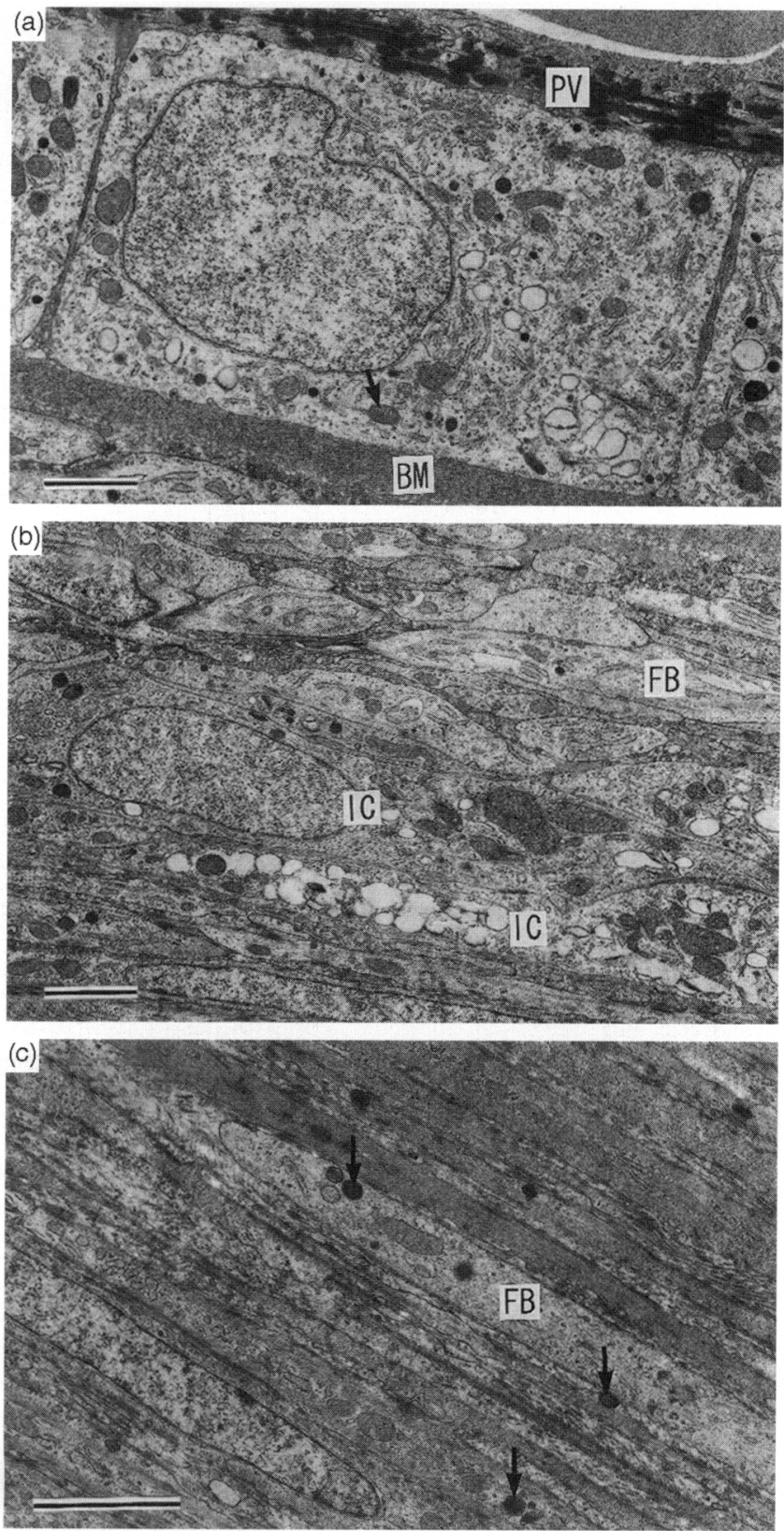

Fig. 2. Electron micrographs of the wall of a follicle from a chicken in which the germinal disc region was destroyed by localized freezing $15 \mathrm{~h}$ before examination. Micrographs are of the follicular wall excluding the disc region. (a) Granulosa layer: there is a development of cristae in the mitochondria of granulosa cells (arrow) compared with those of the control follicle (Fig. 1a). PV: perivitelline layer; BM: basement membrane. (b) Theca interna: the number of lipid droplets is markedly increased in the interstitial cells compared with that of the control follicle (Fig. Ib). FB: fibroblast; IC: interstitial cell. (c) Theca externa: fibroblasts in the theca externa contain more dense bodies (arrows) than does the control follicle (Fig. Ic). Scale bars represent $2 \mu \mathrm{m}$.

Twenty hours after destruction of the germinal disc region, follicles were undergoing bursting atresia (Fig. 3). Granulosa cells contained mitochondria with the same developed inner structure as observed $15 \mathrm{~h}$ after destruction of the germinal
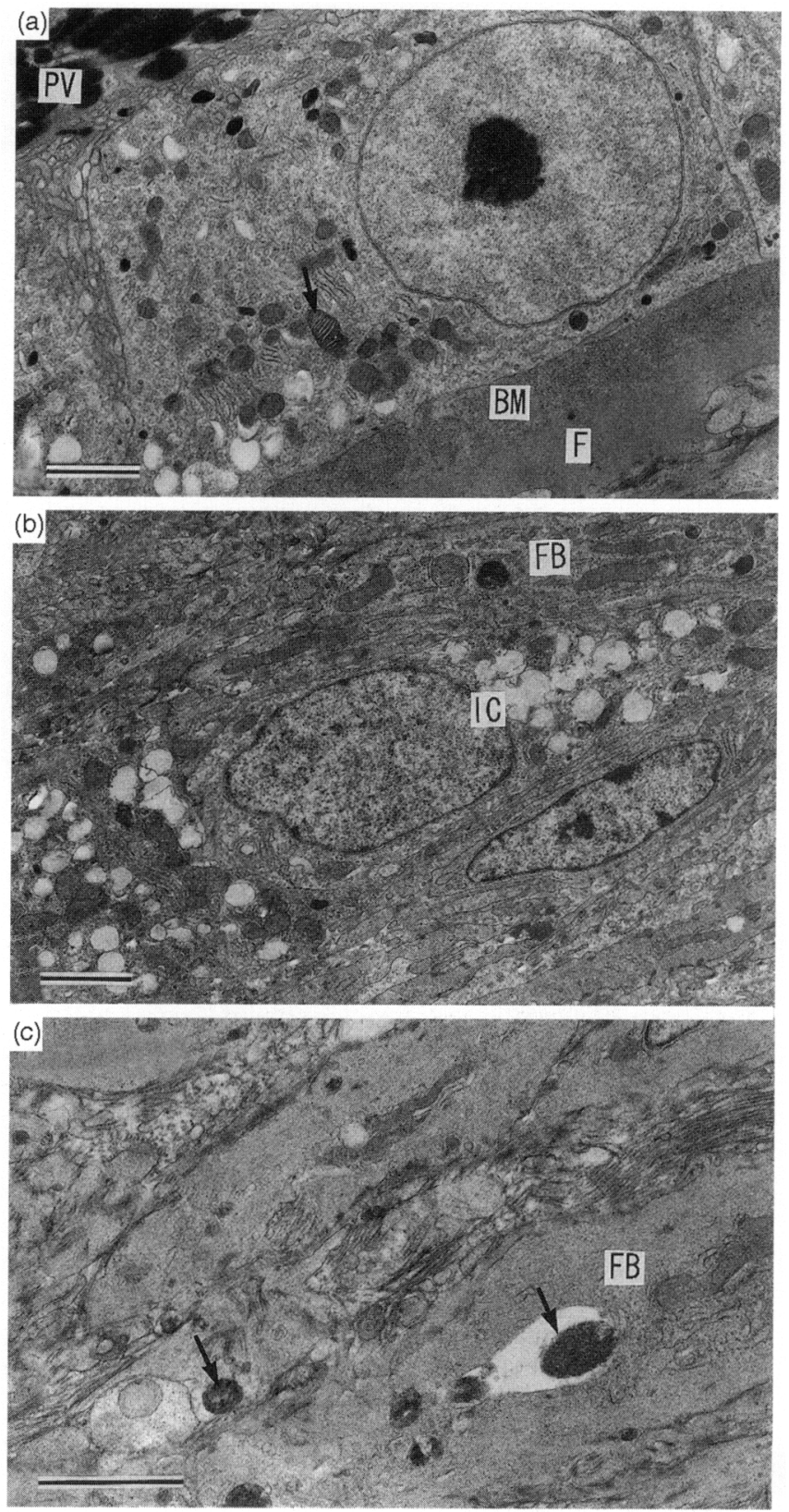

Fig. 3. Electron micrographs of the wall of a follicle from a chicken in which the germinal disc region was destroyed by localized freering $20 \mathrm{~h}$ before examination. Micrographs are of the follicular wall excluding the germinal disc region. (a) Granulosa layer: granulosa cells contain mitochondria with developed cristae and dense matrix (arrow) as well as increased amounts of lipid droplets. Fluid $(F)$ has accumulated in the space formed between the basement membrane and theca interna. PV: perivitelline layer; BM: basement membrane. (b) Theca interna: interstitial cells (IC) and fibroblasts (FB) are round, and interstitial cells contain a large number of lipid droplets. (c) Theca externa: fibroblasts contain dense bodies (arrows), and collagenous bundles have disintegrated. Scale bars represent $2 \mu \mathrm{m}$.

disc region, whereas other organelles exhibited normal features. Some granulosa cells had increased amounts of lipid droplets. Fluid had accumulated in the space formed between the basement membrane and theca interna (Fig. 3a). Interstitial cells 
and fibroblasts in the theca interna were round in appearance owing to shrinkage of the theca layer. The interstitial cells contained a markedly increased number of lipid droplets (Fig. 3b). In the theca externa, fibroblast-like cells revealed a contracted appearance, and collagen fibres were dissociated. Fibroblast-like cells contained markedly enlarged dense bodies, suggesting the activation of lysosomal enzymes (Fig. 3c). These structural changes of the follicular wall after destruction of the germinal disc region were observed consistently in the four experiments.

\section{Discussion}

It was found that destruction of the germinal disc region by localized freezing induces atretic changes of follicular tissues. Development of the inner structure of mitochondria of granulosa cells and accumulation of lipid droplets in the thecal interstitial cells were observed in follicles $15 \mathrm{~h}$ after destruction of the germinal disc region. Degenerative changes, including hydrolysis by lysosomal enzymes, were present in the thecal fibroblast-like cells $20 \mathrm{~h}$ after destruction of the disc region.

The major difference between the germinal disc region and the rest of the follicular wall is the germinal disc-granulosa cell complex. The thecal tissue overlying the germinal disc region is essentially similar in structure to the rest of the theca (Perry et al., 1978). The germinal disc is considered as the metabolic centre of the oocyte because ooplasmic organelles, such as the germinal vesicle and mitochondria, are condensed in this region (Yoshimura et al., 1993a, b). Therefore, the metabolic functions of the oocyte are lost when the germinal disc region is destroyed, whereas destruction of other areas of the follicular wall have no significant effect on the metabolic activities of the oocyte. The granulosa cells overlying the germinal disc are in an active proliferative state (Perry et al., 1978) and are less differentiated than are granulosa cells located in other areas (Marrone et al., 1990). It is assumed that these histological differences are the reason why destruction of the germinal disc region but not of other areas has different effects on follicular growth and maintenance of the integrity of the follicular tissues.

Structural changes in the granulosa and theca layers after destruction of the germinal disc region suggest that the synthesis of steroids by the granulosa and theca layer, the major sites of steroidogenesis, is affected. Mitochondria of steroid-producing cells contain enzymes essential for steroidogenesis and lipid droplets in these cells contain mitochondrial substrates for steroid synthesis. In the current study, we found that the density of the matrix and the number of mitochondrial cristae in granulosa cells had increased $15 \mathrm{~h}$ after destruction of the germinal disc region. Accumulation of lipid droplets in the granulosa and thecal interstitial cells was observed $20 \mathrm{~h}$ after destruction of the germinal disc region. This increase in the number of lipid droplets was also observed in follicles undergoing atresia induced by hypophysectomy (Yoshimura ef al., 1993c). Therefore, it is assumed that steroidogenic activities are reduced in these follicles after destruction of the germinal disc region, supporting our previous report that the destruction of the disc region suppresses the preovulatory increase in serum progesterone (Yoshimura et al., 1994).
The mechanism by which the oocyte controls follicular steroidogenesis has yet to be confirmed. The presence of gap junctions between the granulosa cells and oolemma in the germinal disc region (Yoshimura et al., 1993b) suggests that cell-to-cell communications are involved in the regulation of their functions including the granulosa cell steroidogenic activity. In addition, recent reports have suggested that growth factors modulate LH stimulation of progesterone production by granulosa cells (Pulley and Marrone, 1986). If the oocyte secretes such factor(s), these factors may regulate steroidogenic activity of granulosa cells. Isolation of these putative growth factors produced by the oocyte is required to test this hypothesis. Studies in mammals have suggested that the oocyte may regulate steroidogenesis and differentiation of granulosa cells from preantral and antral follicles (Hubbard and Erickson, 1988; Vanderhyden et al., 1990, 1992).

Thecal fibroblast-like cells that have contractile activity (Yoshimura et al., 1983; Van Nassauw et al., 1992, 1993) and granulosa cells contain receptors for progesterone (Yoshimura and Bahr, 1991) and androgens (Yoshimura et al., 1993d). Kamiyoshi et al. (1986) reported that granulosa cells contain oestrogen receptors. These reports suggest that follicular tissues are the target sites for steroid hormones. We observed that hypophysectomy induces follicular atresia in chickens. However, administration of progesterone or oestradiol to hypophysectomized chickens prevents follicles from becoming atretic (Yoshimura and Tamura, 1986; Yoshimura et al., 1993c). In the present study, hydrolysis of thecal fibroblasts by lysosomal enzymes was observed after the destruction of the germinal disc region, as has been observed in atretic follicles of hypophysectomized chickens (Yoshimura et al., 1993c). Decreased steroid hormone production by the follicle may result in the degeneration of thecal fibroblasts, and bursting of the follicular wall may eventually occur.

In conclusion, results obtained in this and previous studies indicate that the germinal disc region of the avian follicle has an important role in the regulation of follicular steroidogenesis and integrity, and that this regulation may be essential for follicular growth. It is not yet possible to separate the germinal disc from its overlying granulosa cells attached by microvilli, and therefore it cannot be determined whether the germinal disc or the germinal disc region is the principal regulator of follicular growth. Elucidation of the mechanism by which the germinal disc or the germinal disc region influences follicular function requires further investigation.

This work was supported in part by the grants from Kieikai Foundation (Tokyo, Japan) and Grants-in-Aid from Ministry of Education, Science and Culture of Japan (No. 0660356).

\section{References}

Hubbard GM and Erickson GF (1988) Luteinizing hormone-independent luteinization and ovulation in the hypophysectomized rat: a possible role for the oocyte? Biology of Reproduction 39 183-194

Jackson JA, Zhang P and Bahr IM (1993a) Plasminogen activator activity in preovulatory follicles during the ovulatory cycle of the chicken Biology of Reproduction 49 1141-1146

Jackson JA, Tischkau SA, Zhang P, Yoshimura Y and Bahr JM (1993b) Involvement of plasminogen activator and collagenase and changes in extracellular matrix during the proliferative and ovulatory phases of the chicken ovary. In 
Avian Endocrinology pp 309-320 Ed. PJ Sharp. Journal of Endocrinology Ltd, Bristol

Kamiyoshi M, Niwa T and Tanaka K (1986) Nuclear estrogen receptors binding in granulosa cells and estradiol-17 $\beta$ in follicular membranes of the ovary of the hen during the ovulatory cycle General and Comparative Endocrinology 61 428-435

Marrone BL, Jamaluddin M and Hertelendy F (1990) Regional pattern of cell maturation and progesterone biosynthesis in the avian granulosa cell layer Biology of Reproduction 42 405-412

Perry MM, Gilbert AB and Evans AJ (1978) The structure of the germinal disc region of the hen's ovarian follicle during the rapid growth phase journal of Anatomy 127 379-392

Pulley DD and Marrone BL (1986) Inhibitory action of epidermal growth factor on progesterone biosynthesis in hen granulosa cells during short term culture: two sites of action Endocrinology 118 2284-2291

Tilley JL, Kowalski KI, Li Z, Levorse JM and Johnson AL (1992) Plasminogen activator activity and thymidine incorporation in avian granulosa cells during follicular development and the periovulatory period Biology of Reproduction 46 195-200

Van Nassauw, Callebaut M, Harrisson F and Scheuermann DW (1992) Smooth muscle cells in the walls of ovarian follicles in the Japanese quail Cell and Tissue Research 269 49-56

Van Nassauw, Sys SU, Harrisson F and Callebaut M (1993) In vitro study of the contractility of the wall of the preovulatory follicle in the Japanese quail Biology of Reproduction 49 359-364

Venderhyden BC, Caron PJ, Buccione R and Eppig IJ (1990) Developmental pattern of the secretion of cumulus-expansion enabling factor by mouse oocytes and the role of oocytes in promoting granulosa cell differentiation Developmental Biology 140 307-317
Venderhyden BC, Telfer EE and Eppig JJ (1992) Mouse oocytes promote proliferation of granulosa cells from preantral and antral follicles in vitro Biology of Reproduction 46 1196-1204

Wang L, Croze F, Morley P and Tsang BK (1993) Granulosa-theca cell interactions in the regulation of plasminogen activator activity during ovarian follicular development in the hen Biology of Reproduction 49 924-932

Yoshimura Y and Bahr JM (1991) Localization of progesterone receptors in preand postovulatory follicles of the domestic hen Endocrinology 128 323-330

Yoshimura $Y$ and Tamura T (1986) Effects of estradiol administration on the follicular tissue of hypophysectomized hens Poultry Science 65 1808-1810

Yoshimura Y, Tanaka K and Koga $O$ (1983) Studies on the contractility of follicular wall with special reference to the mechanism of ovulation in hens British Poultry Science 24 213-218

Yoshimura Y, Okamoto T and Tamura T (1993a) Ultrastructural changes of oocyte and follicular wall during oocyte maturation in the Japanese quail (Coturnix coturnix japonica) Journal of Reproduction and Fertility 97 189-196

Yoshimura Y, Okamoto T and Tamura T (1993b) Electron microscope observations on LH-induced oocyte maturation in Japanese quail (Coturnix coturnix japonica) Journal of Reproduction and Fertility 98 401-407

Yoshimura Y, Bahr JM, Okamoto T and Tamura T (1993c) Effects of progesterone on the ultrastructure of preovulatory follicles of hypophysectomized chickens: possible roles of progesterone in the regulation of follicular function Japanese Poultry Science 30 270-281

Yoshimura Y, Chang C, Okamoto T and Tamura T (1993d) Immunolocalization of androgen receptor in the small, preovulatory, and postovulatory follicles of laying hens General and Comparative Endocrinology 91 81-89

Yoshimura Y, Tischkau SA and Bahr IM (1994) Destruction of the germinal disc region of an immature preovulatory follicle suppresses follicular maturation and ovulation Biology of Reproduction 51 229-233 